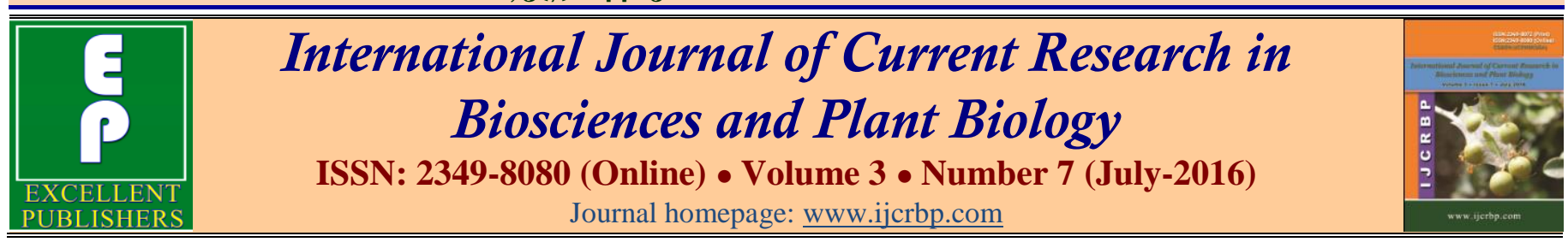

\title{
Selective and Interbreeding of Freshwater Ornamental Shrimps with Endemic Aquarium Plants
}

\author{
Ganesh Ariyanathan* and J. Sesh Serebiah \\ Jehovah Shamma Centre for Marine and Wildlife Research, Mudiveeranpattinam, Ramanathapuram Dt-623 513, \\ Tamil Nadu, India \\ *Corresponding author.
}

\begin{abstract}
A bstract
Shrimp are decapods or 10 limbed crustaceans along with crayfish, cherax crabs and others. Historically only crayfish were kept, in the last 10-15 years shrimp and other crustaceans have become increasingly popular in home aquaria. Three endemic species Indian Dwarf Shrimp, "Rainbow" Shrimp Neocardina zeylanica, Indian White banded Shrimp Caridina cf. babaulti var. Indian white banded, Stripe Shrimp Caridina cf. babaulti and an exotic species Red Cherry Shrimp Neocaridina denticulata sinensis "red" were bred commercially by developing hatchery technology. Availability of these endemic species in the ornamental market will reduce the stress on wild population as they are wild caught for their commercial demand. The life cycle of the selected shrimp species were studied in detail and recorded. The Planktonic larval stages are completely suppressed and the larvae assume a benthic lifestyle after hatching, i.e., they are miniature versions of the adults. In the process of selective breeding, commercially sold feeds haven given better colour enhancement than natural feeds. Interbreeding among these shrimp species resulted in hybrids resembling their wild variants.
\end{abstract}

\section{Article Info}

Accepted: 05 June 2016

Available Online: 06 July 2016

\section{Ke ywords}

Endemic plants

Hatchery

Hybrids

Interbreeding

Ornamental shrimps

Selective breeding

\section{Introduction}

The practice of shrimp keeping has developed among hobbyist to control algal formation in planted aquariums (Heerbrandt, T.C. and J. Lin, 2006). The main aim of the work is to focus on endemic freshwater shrimps that have ornamental value. Their biology, behavior, adaptability in aquarium conditions and color enhancement by feed formulations and selective breeding are being studied. Currently the industry is completely depends on the wild caught species (Raghavan et al, 2014). Breeding and production of high grade 'Rainbow shrimps', 'Stripe shrimps', 'White banded shrimps' will definitely reduce the stress on the wild population. Rainbow shrimps have potential market for their 'algae eating' ability despite its subdued coloration. By improving the pigmentation, its demand can be increased both in domestic and international markets. For pigment enhancement, blanched carrot, cucumber, dried grapes and mixture of commercial shrimp foods were administrated and results were encouraging. The objectives of the present study are given below.

- Maintenance of fresh water ornamental shrimps brood stocks with endemic aquarium plants.

- Standardization of hatchery technology of fresh water ornamental shrimps.

- Selective breeding of fresh water ornamental shrimps for the production healthy strains with desirable character.

- Interbreeding of fresh water ornamental shrimps for the production of novel attractive strains for trade. 


\section{Materials and methods}

\section{Maintenance of fresh water ornamental shrimps brood stocks with endemic aquarium plants}

Brood stocks of each species (three endemic species 'Rainbow shrimps', 'Stripe shrimps', 'White banded shrimps' and one exotic species-'Red cherry shrimps') were maintained in separate glass tanks $(40 \times 20 \times 25$ $\mathrm{cm})$ supported with bio-chemical filter systems. Plants growth is aided with Compact Florescent lamp at a ratio of 1watt per 5 liters, Mopani driftwood and suitable soil substrates. About 10 females and 10 males used were with average total length of $2.5 \pm 0.5 \mathrm{~cm}$ and placed into two separated tanks. Only females with saddle and healthy males were used. All the shrimps were procured from the koluthur, Chennai (Hub for aquarium trade). Each individual shrimps were carefully inspected for disease and abnormalities. The Shrimps were acclimatized for 15 minutes and then released into their respective tanks.

\section{$\mathrm{CO}_{2}$ system}

To aid plants growth in the brood stock tanks, $\mathrm{CO}_{2}$ were supplied. Initially to reduce the running cost of the operation, improvised method was used where a mixture of water, sugar and yeast were used to produce $\mathrm{CO}_{2}$.

The main disadvantage of the improvised method is that the $\mathrm{CO}_{2}$ supply cannot be fully regulated. The level of $\mathrm{CO} 2$ was estimated by 'Drop Checker' with $4 \mathrm{dkh}$ Brmothymol blue solution. The desired $\mathrm{CO}_{2}$ level is 30 ppm.

\section{Lighting}

After the initial setup, a photoperiod of $6 \mathrm{hrs}$ is maintained. Then after couple of weeks, 8-9 hrs of photoperiod is maintained. Frequent change in photoperiod resulted in the formation of algal growth and throwing the plants off their routine and to compensate this automatic timer was used later. For lighting, Compact Florescent lamp at a ratio of 1 watt per 5 liters was used.

\section{Fertilizers}

Not enough shrimps in the tank to provide fertilizers to the plants in this case, fertilizers tabs are inserted near the roots.

\section{Water parameters}

The selected species prefer soft, acidic water with temperatures of about $26^{\circ} \mathrm{C}$. For each shrimp species the water parameters are different. High temperatures will reduce the lifespan of the shrimps, lower temperatures increases the amount of dissolved oxygen, and higher temperature reduces the amount of dissolved oxygen. Although keeping shrimps in lower temperature helps prolong their life, it'll decrease their appetite and breeding rate. The 3 most important parameters are $\mathrm{PH}$, $\mathrm{GH}$, and $\mathrm{KH}$. These 3 are the main deciding factors in establishing optimal parameters for the shrimps. Maintaining stable parameters is one of the most important aspects in keeping shrimp. Shrimp need clean water, so 30 percent of water was changed at least once every two weeks. Aeration was provided throughout the study period. Shrimp are especially sensitive to chlorine or chloramines in city water supplies, so care was taken to use a dechlorinator or ammonia neutralizer to remove these chemicals. Quality products that neutralize ammonia are important. If chlorine and/or ammonia aren't eliminated, it would result in mortality. Invertebrates especially shrimp are very sensitive to copper. So care was taken not to treat an aquarium with any copper-containing products. Copper is not the only thing that can harm shrimp. Many of the anti-parasite products on the market will have devastating results on shrimp, so this is just another good reason to have a shrimp-only aquarium. The kits or apparatus used were; DO meter (dissolved oxygen and temperature) and API aquarium freshwater test kit ( $\mathrm{pH}$, ammonia, and nitrite). Measurements were taken twice a week.

\section{Shrimp feed}

For pigment enhancement, blanched carrot, cucumber, dried grapes and mixture of commercial shrimp foods were administrated and results were encouraging. Some of the commercialized colours enhancing foods are Hakari Crab bites, Spirulina, Tetra Colour bites and Hikirai Agar wafers.

\section{Endemic plants}

Aquatic plants are not only an ideal background to showcase the aquatic habitat, but they're also improving water quality by allowing biological filtration, removing nitrates, and oxygenating the water. Plants maintained in the brood stock tanks are as follows: Cryptocoryne cognata, Rotala macarandras, Rotala indicas, Hygro difformis. 


\section{Standardization of hatchery technology of fresh water ornamental shrimps}

Important details of shrimp species experimented in the present study are given below (Fig. 1).

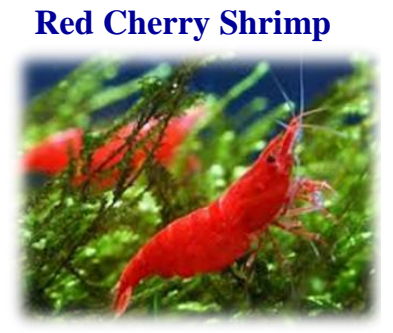

Indian White banded Shrimp

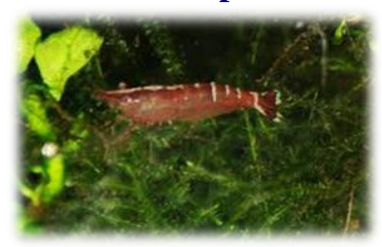

Fig. 1: Shrimp species used in the study.

Common Name: Red Cherry Shrimp

Scientific Name: Neocaridina denticulata sinensis "red"

Holthuis (1993) stated that N.d. sinensis was placed under the genus Caridina before being reclassified under Neocaridina.

Size: up to $3 \mathrm{~cm}$

Origin: Taiwan (Hung et al., 1993) this red variety does not occur naturally anywhere, but originally bred in Taiwan. Wild form occurs in Southern China and Taiwan.

Larval Development Type: Completely Suppressed (Shokita, 1981; Shy, 1994): Larvae assume a benthic lifestyle after hatching, i.e. they are miniature versions of the adults (Yang, H.J. and H.S. Ko, 2003). There is no planktonic larval stage.

Common Name: Indian Dwarf Shrimp, "Rainbow" Shrimp Scientific Name: Neocardina zeylanica

Size: $2-2.5 \mathrm{~cm}$

Origin: India (North East), might be more widely spread in south Asia.

Larval Development Type: Completely Suppressed (Shokita, 1981; Shy, 1994): Larvae assume a benthic lifestyle after hatching (Yang, H.J. and H.S. Ko, 2003), i.e. they are miniature versions of the adults. There is no planktonic larval stage. The hatchlings of this shrimp are extremely small and grow slowly.
Common Name: Indian White banded Shrimp

Scientific Name: Caridina cf. babaulti var. Indian white banded

Size: $2.5-3 \mathrm{~cm}$

Origin: India (North East), might be more widely spread in south Asia.

Larval Development Type: Completely Suppressed (Lai, H.T. and J.Y. Shy, 2009): Larvae assume a benthic lifestyle after hatching, i.e. they are miniature versions of the adults (Yang, H.J. and H.S. Ko, 2003). There is no planktonic larval stage. The hatchlings of this shrimp are extremely small and grow slowly.

Common Name: Stripe Shrimp

Scientific Name: Caridina cf. babaulti

Size: $2.5-3 \mathrm{~cm}$

Origin: India

Larval Development Type: Completely Suppressed (Lai, H.T. and J.Y. Shy, 2009): Larvae assume a benthic lifestyle after hatching (Yang, H.J. and H.S. Ko, 2003), i.e. they are miniature versions of the adults. There is no planktonic larval stage. The hatchlings of this shrimp are small and grow slowly.

\section{Materials used}

Glass tanks $(40 \times 20 \times 25 \mathrm{~cm})$ supported with biochemical filters are used. External filters and power head filers are not used to avoid the suction of larvae. Hatchery tanks are maintained without soil substrate but mosses are maintained on bog wood and quart stone. The biofilm produced by the moss was used as nourishment for the larvae.

\section{Results and discussion}

\section{Stripe shrimp Caridina $c f$. babaulti}

The selected species reached first maturity at around 75 days old with TL $2.3 \pm 0.2 \mathrm{~cm}$ (Demas, 2007). Upon reaching maturity, the presence of visible ovaries can be seen through the cephalothorax region of the females. Appendix masculina on the second pleopod were observed in males (Kubo, 1938), Similar observation was reported by Englund and Cai (1999). Ten pairs of matured male and female shrimps were placed in breeding tank. Mating process usually take place 1-3 day(s) after the introduction of male and female into the same tank. Female molted prior to mating. Observation was carried until female shrimp become ovigerous. 
Both molting and mating occurred rapidly in less than 10 sec. During mating process male and female will be facing each other and sperm were deposited into the genital opening of female using its appendix masculina. The eggs were fertilized when it passed through the sperm on the way to the brood pouch. The pouch was formed by pleopods and overhanging of pleura of the female. A day after mating, female was observed to carry fertilized eggs, fan and incubated in the brood pouch until hatch. According to Adiyodi and Adiyodi (1994) this kind of parental care will result in higher survival rate of larva produced. Similar to those reported by Schram (1986). Fertilized eggs were oval in shape, vary from greenish to yellowish in color. The egg size was comparatively large, with an average length $1.19 \mathrm{~mm}$. Thin ribbon-like filament binds the eggs in grape-like bunches and attached it to the female's pleopod. The membrane can hardly be distinguished since it is thin, transparent and lying close to the surface. Smaller females produced fewer eggs compared to larger females (Ketse, 2006).

Number of larvae produced by each female was counted and recorded (Fig. 2). After a week, only healthy larvae were used for the next experiment.

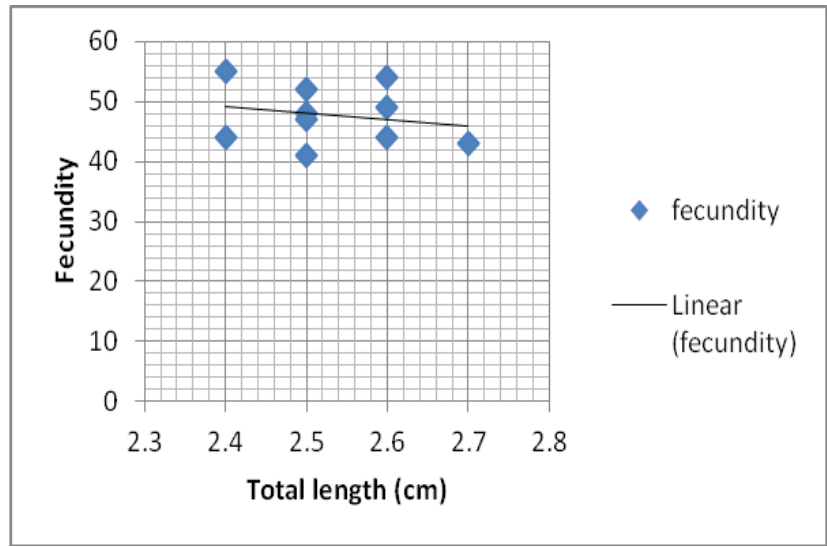

Fig. 2: Fecundity by length for Caridina cf. babaulti.

\section{Selective breeding of fresh water ornamental shrimps for the production healthy strains with desirable character}

\section{Selective breeding of Indian White Banded Shrimp Caridina cf. babaulti var. Indian white banded}

A dozen of mature Indian White banded Shrimps were procured from the Kolathur Market, Chennai, South Asia largest hub for ornamental fish industry. The sex ratio was 1:5 (Male: female) If the number of males is not enough, it will decrease the rate of successful mating. On the other hand, to Prevent female death from being exhausted because of being chased by multiple males. Some more plants were grown to provide hidden places.

Traits selected for selective breeding are:

- Thickness of the body colour

- Shape of the tail

- Overall size of the shrimp

- Pattern of bands and spots

- Thickness of the white bands

- Redness of the legs

After successful mating, berried females were allowed to stay in the same tank for 3-4 days and then move them carefully and slowly to the tank rich of moss and microorganisms. Using the genetic algorithm for selective breeding:

Method 1: Keeping the most desirable traits from the parents and passing it onto the offspring, not losing the traits in the offspring.

Method 2: All genes are randomly selected between two of the most elite male and female generations and part of the genetic info is exchanged. With the accumulation of the desired genetic information, we hope to achieve superior offspring.

Using these methods, F4 generations were able to retain and come up with desirable colour patterns.

\section{Selective breeding and colour enhancement by feed formulations}

Fifty larvae (one week old) were placed in a tank. Observation was carried out until all the larvae reached first maturity. Then two dozens of brightly coloured red cherry shrimps were separately maintained in two glass tanks. Both the groups of shrimps were given same amount of photoperiod, $\mathrm{CO}_{2}$ injection, and plant composition. One of the groups (1) was exposed to different kinds of commercialized colour enhancing feeds such as Hakari Crab bites, Spirulina, Tetra Colour bites and Hikirai Agar wafers and the other group (2) had been administrated with natural food such as blanched carrot, cucumber and algae. After 12 moultings, the observations were made and recorded. The shrimps that were administrated with commercialized food showed improved red colouration compared with the group of shrimp fed with natural food (Fig. 3). 


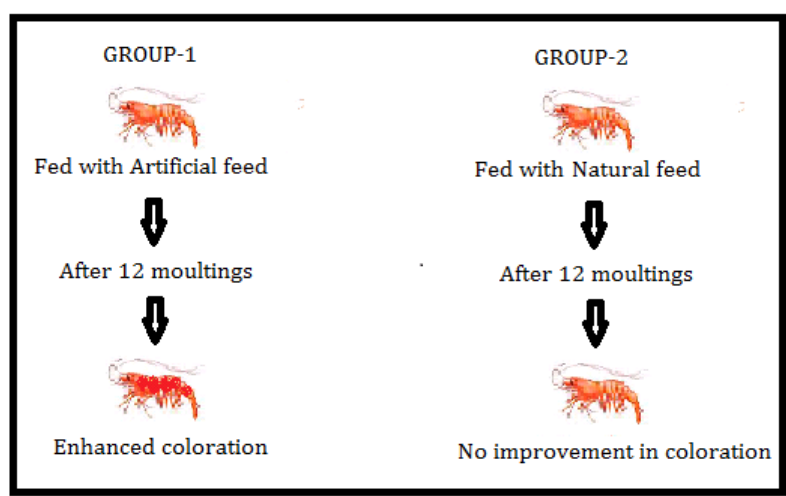

Fig. 3: Red Cherry Shrimps fed with artificial and natural feed.

The same procedure had been followed for the selected endemic species and the results were same. The F1 generation larva were segregated from the two groups of shrimps and separately maintained in two different tanks and they were allowed breed.

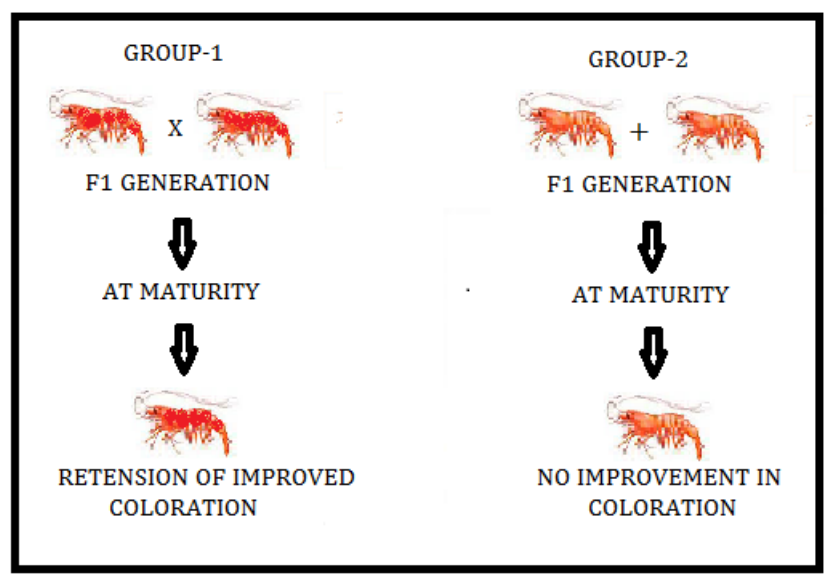

Fig. 4: F1 crossing in Red Cherry Shrimps.

The F2 generation of Group-1 shrimps was able to retain the improved coloration from F1 parents in spite of feeding the F2 generation shrimp with natural feed. Where as in Group-2, shrimps of F2 generation did not show any major changes in their body coloration (Fig. 4).

\section{Interbreeding of fresh water ornamental shrimps for the production of novel attractive strains for trade}

The wild variant of the Red Cherry Shrimp Neocaridina denticulata sinensis is actually colorless and its Red color is due to intensive and repeated selective breeding and hence the name Red Cherry Shrimp. Interbreeding among these species resulted in colorless hybrids which represent their true wild variants. Same results were witnessed when F1 generation were interbred (Figs. 5 and 6).

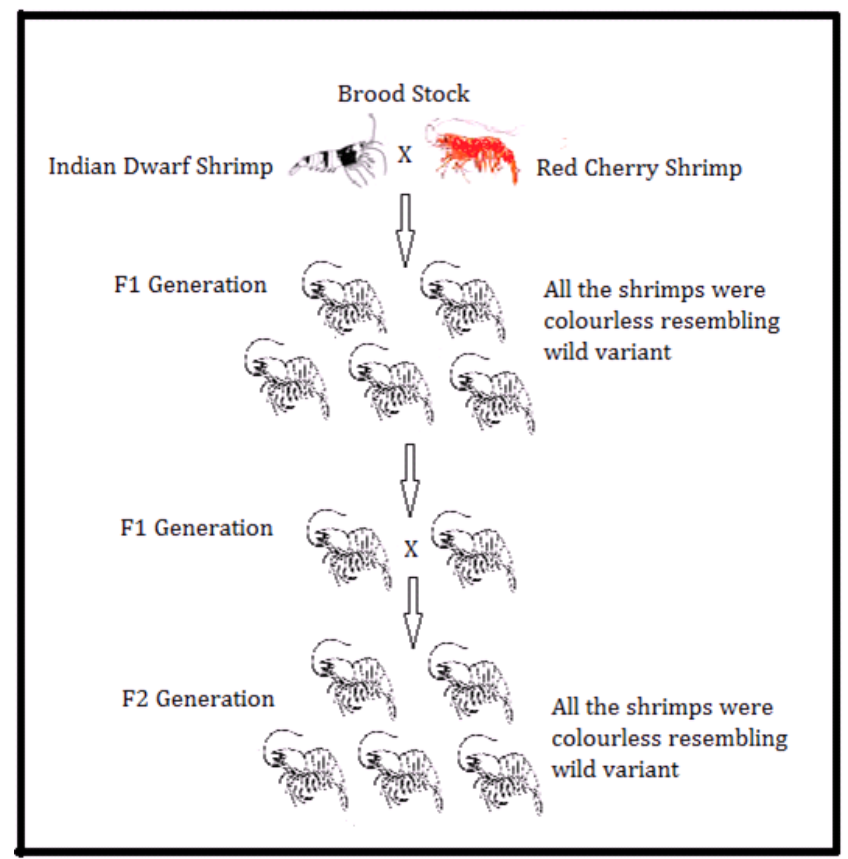

Fig. 5: Interbreeding between Indian Dwarf Shrimp and Red Cherry Shrimp.

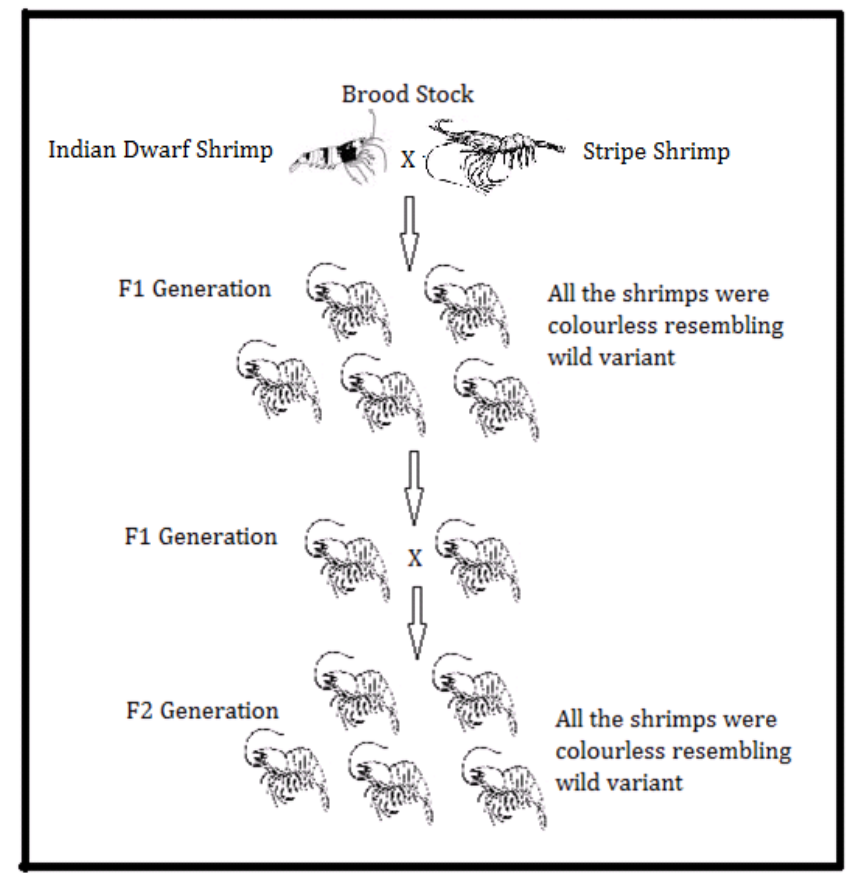

Fig. 6: Interbreeding between Indian Dwarf Shrimp and Stripe Shrimp.

The wild variant of Indian White Banded Shrimp is light red in colour. So interbreeding of these species with Red Cherry Shrimps and Indian dwarf shrimps results in hybrids that $50 \%$ of the population is red and rest are colorless. Same results were witnessed when F1 generation were interbred Fig.7. 
The life cycle of the four selected species were studied in detailed and recorded. In all the four species planktonic larval stages are completely suppressed and the larvae assume a benthic lifestyle after hatching, i.e. they are miniature versions of the adults. The study was succesful in developeing the hatchery technology and commercilaising it. The life cycle of the four species were almost same and water parameters especially water temperature played a crucial part in breeding these species. The Fecundity of the shrimp species is propotionate to its total length.

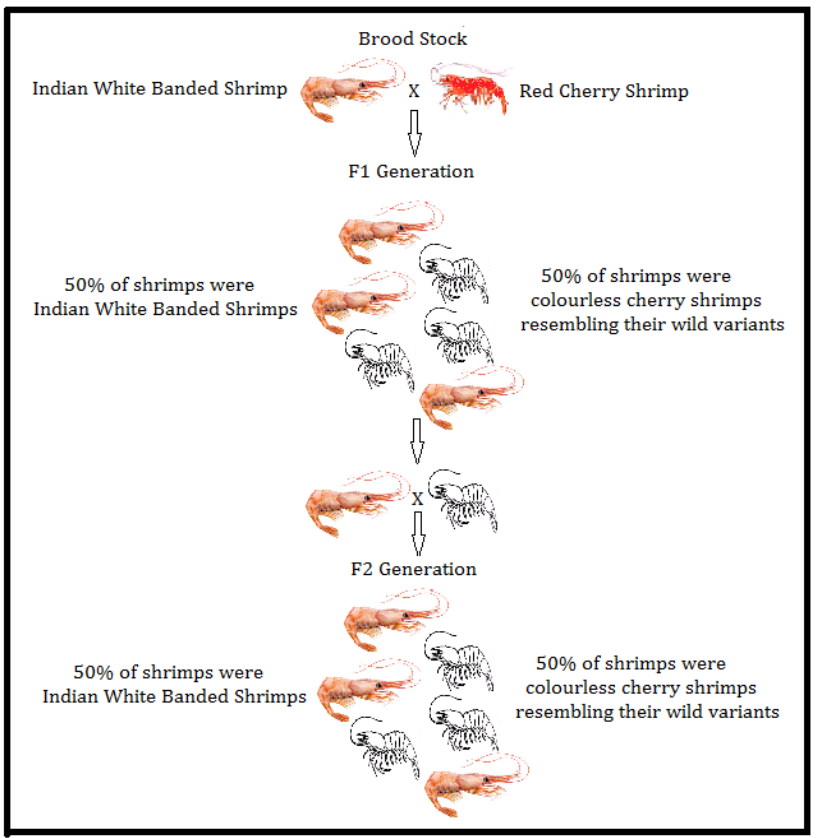

Fig. 7: Interbreeding between Indian White Banded Shrimp and Red Cherry Shrimp.

In colour enhancement procedures, commercially sold feeds have given better results than the natural feeds. Test samples that are fed with commercial feeds were able to retain enhanced colouration up to F2 generation.

Interbreeding among these shrimp species resulted in hybrids resembling their wild variants. Apart from Indian White banded Shrimp Caridina cf. babaulti var. Indian white banded which is red in colour by origin; other selected species are colourless by origin or by wild variant.

The wild variant of the Red cherry shrimp Neocaridina denticulata sinensis is actually colorless and its red color is due to intensive and repeated selective breeding and hence the name Red Cherry Shrimp. Interbreeding with Red Cherry Shrimps resulted in colorless hybrids which represent their true wild variants (Fig 8).

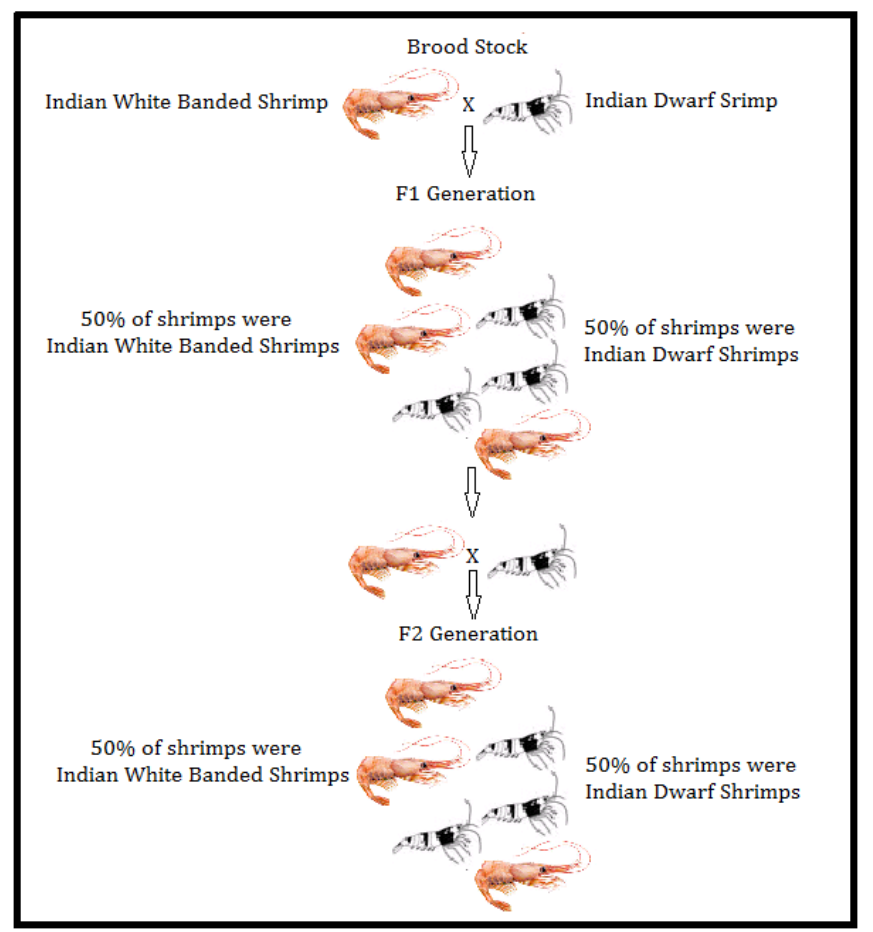

Fig. 8: Interbreeding between Indian Dwarf Shrimp and Indian White Banded Shrimp.

\section{Conflict of interest statement}

Authors declare that they have no conflict of interest.

\section{References}

Adiyodi, K.G., Adiyodi, R.G., 1994. Reproductive Biology of Invertebrates, Vol. 6, Part B: Asexual Propagation and Reproductive Strategies. John Wiley, USA.

Demas, P., 2007. Red Cherry Shrimp. Trop. Fish Hobbyist. 56, 90-92.

Englund, R.A., Cai, Y., 1999. The occurrence and decription of Neocaridina denticulata sinensis (Kemp, 1918) (Crustacea: Decapoda: Atyidae), a new introduction to the Hawaiian Islands. Bishop Museum Occasional Papers No. 58. Pp.58-65.

Heerbrandt, T.C., Lin, J., 2006. Larviculture of red front shrimp, Caridina gracilirostris (Atyidae, Decapoda). J. World Aquacult. Soc. 37, 186-190.

Holthuis, L.B., 1993. The Recent Genera of Caridean and Stenopodidean Shrimps (Crustacea, Decapoda): With an Appendix on the Order Amphionidacea. National Natuurhistorisch Museum, Lieden, Netherlands. 328p.

Hung, M.S., Chan, T.Y., Yu, H.P., 1993. Atyid shrimps (Decapoda: Caridea) of Taiwan, with descriptions of three new species. J. Crustacean Biol. 13, 481-503.

Ketse, N., 2006. The Effects of Selected Reference Toxicants on Embryonic Development of the Freshwater Shrimp Caridina nilotica(Decapoda: Atyidae). M.Sc. 
Thesis, Institute for Water Research, Rhodes University, Grahamstown, South Africa.

Kubo, I., 1938. On the Japanese atyid shrimps. J. Imperial Fish. Inst. 33, 67-100.

Lai, H.T., Shy, J.Y., 2009. The larval metamorphosis of Caridina pseudodenticulata (Crustacea; Decapoda; Atyidae) rearing in the laboratory, with a discussion of larval metamorphosis types. Raffles Bull. Zool. 20, 97109.

Raghavan, R., Dahanukar, N., Philip, S., Iyer, P., Kumar, B., Daniel, B., Molur, S., 2014. The conservation status of decapod crustaceans in the Western Ghats of India: An exceptional region of freshwater biodiversity. Aquatic Conserv: Mar. Freshw. Ecosyst. 25, 259-275.

Schram, F.R., 1986. Crustacea. Oxford University Press, Oxford. Shokita, S., 1981. Life-history of the family Atyidae (Decapoda, Caridea). Aquabiol. 12, 15-23.

Shy, J.Y., 1994. Taxonomy, Distribution and Ontogeny of Freshwater Shrimps and Crabs in Taiwan. Ph.D. Thesis, National Taiwan Ocean University, Keelung.

Yang, H.J., Ko, H.S., 2003. Larval development of Neocaridina denticulate sinensis (Decapoda: Caridea: Atyidae) reared in the laboratory. Korean J. Syst. Zool. 19, 49-54.

\section{How to cite this article:}

Ariyanathan, G., Sesh Serebiah, J., 2016. Selective and interbreeding of freshwater ornamental shrimps with endemic aquarium plants. Int. J. Curr. Res. Biosci. Plant Biol. 3(7), 144-150.

doi: http://dx.doi.org/10.20546/ijcrbp.2016.307.020 